\title{
MONITORING OF THE ASSOCIATED COURSE OF LEPTOSPIROSIS AND BABESIOSIS IN DOGS OF THE SUMY REGION OF UKRAINE
}

\author{
Olha Turchenko \\ Department of Virology, Patanatomy and Poultry Deseases \\ Sumy National Agrarian University \\ 160 Herasyma Kondratieva str., Sumy, Ukraine, 40021 \\ olga.turchenko.vet@gmail.com
}

\begin{abstract}
Leptospirosis and babesiosis in dogs may be associated. These diseases often have similar symptoms and mask each other, or are asymptomatic, which complicates the diagnosis, significantly worsens the prognosis and reduces the survival of sick animals. Monitoring of the associated course of leptospirosis and babesiosis in dogs makes it possible to study the frequency of this parasitocenosis in dogs and the peculiarities of its course, which is the basis for improving the diagnosis and treatment of sick animals.

The aim of the research. Monitor the associated course of leptospirosis and babesiosis in dogs.

Methods. The research was conducted in the private veterinary clinic «Vetservice» in Sumy and in the serology department of the Sumy Regional State Laboratory of the Civil Service of Ukraine for Food Safety and Consumer Protection. Blood samples were taken from dogs came for treatment to the «Vetservice» clinic. The diagnosis of babesiosis was established directly in the clinic by the results of erythrocyte microscopy in thin smears of peripheral blood of sick dogs stained by Giemsa. The diagnosis of leptospirosis was established in the serology department of the Sumy Regional State Laboratory based on the results of a study of the serum of sick dogs in the microagglutination reaction. The subjects of the study were clinically ill and suspected dogs with the associated course of leptospirosis and babesiosis, as well as blood samples from these animals. Babesium trophozoites were detected in erythrocytes under an immersion microscope, a magnification of ocular $10 \times 90$, and the presence of antibodies to leptospira was detected by the presence of agglutination of leptospira in microagglutination reaction.

Results. In the study of the incidence of dogs associated with leptospirosis and babesiosis during 2014-2019, according to the clinic «Vetservice» found that the number of reported cases of associated leptospirosis and babesiosis annually varies from 9 to 28 cases. This parasitocenosis is registered all year round with peaks in spring and autumn, moderately in summer and rarely in winter. Purebred animals get sick several times more often than non pedigree ones. During the period from 2016 to 2019 , the number of diseases in females and males was approximately the same. During the period from 2014 to 2015, males were more often ill.

Conclusions. The prevalence of the associated course of leptospirosis and babesiosis in dogs of the Sumy region of Ukraine was determined with the determination of seasonal, breed and sexual dynamics of this parasitocenosis.

Keywords: associated course of leptospirosis and babesiosis in dogs, laboratory diagnosis of leptospirosis and babesiosis, blood, microagglutination reaction, microscopy.
\end{abstract}

DOI: $10.21303 / 2504-5679.2021 .001616$

\section{Introduction}

The subjects of these studies were clinically ill and suspected dogs associated with leptospirosis and babesiosis, as well as blood samples from these animals. Babesia trophozoites were detected in erythrocytes under an immersion microscope, magnification of ocular $10 \times 90$, and the presence of antibodies to leptospira was detected by the presence of agglutination of leptospira in microagglutination reaction.

Dogs with an associated course of leptospirosis and babesiosis are periodically registered in veterinary clinics around the world, particularly in Europe [1, 2]. These diseases are characterized by a similar course and can mask each other, which delays timely diagnosis, complicates treatment and worsens the prognosis. Under such conditions, it is necessary to study the associated course of leptospirosis and babesiosis in dogs with the study of its course, which will understand the prevalence of this parasitocenosis, help speed up diagnosis and, based on existing clinical cases, develop more effective treatment regimens [3, 4].

Leptospirosis is a common bacterial infection in dogs worldwide, particularly on the European continent $[1,2]$. The relevance of research on this disease is also due to the fact that leptospirosis also affects humans and can be transmitted from animals. Dogs become infected with leptospirosis 
in the absence of annual vaccination, in contact with sick dogs or their urinary marks in the environment, through murine rodents, as well as from productive animals through meat, offal, dairy products contaminated with leptospira [2, 3]. Leptospirosis can occur in sick dogs acutely or chronically, manifesting itself only in the presence of concomitant pathology. The causative agents of leptospirosis in dogs are most often L. icterohaemorrhagiae, L. cnicola, L. grippotyphosa, L. australis [5, 6]. Leptospira affect the kidneys, liver, central nervous system, causing endogenous intoxication due to exo- and endotoxins leptospira and their breakdown products, hemorrhagic syndrome, ulcers on mucous membranes and skin, jaundice, renal and hepatic failure, infectious-toxic. Dogs with leptospirosis often have such non-specific manifestations as anorexia, pyrexia, tremor, weakness, vomiting, diarrhea with or without blood impurities, dark urine color [7, 8].

Babesiosis is a widespread blood-borne parasitic disease of dogs, endemic on all continents, where parasitic mites are registered, which is acute and chronic. The causative agents of the disease are Babesia canis and its subspecies: B. canis canis, B. rossi, B. vogeli, as well as B. gibsoni and B. conradae. Carriers and definitive hosts of babesia are parasitic Ixodes mites of the genera Ixodes, Dermacentor, Haemaphysalis, Hyalomma, Rhipicephalus, which inoculate babesia to warm-blooded intermediate hosts during blood suction [9, 10]. Babesia affects erythrocytes, liver, kidneys, spleen, causing hypoxia and intoxication of all organs and tissues [11, 12]. Babesiosis is characterized by hyperthermia, intoxication, dehydration, anemia, jaundice, splenomegaly, neutrophilia, hemoglobin and thrombocytopenia, hyperbilirubinemia, hemoglobinuria, tachycardia, tachypnea; recently, the presence of bloody diarrhea in patients with babesiosis dogs has been increasingly registered [13, 14].

Babesiosis, like leptospirosis, can be acute or chronic, with clinical manifestations similar to those of leptospirosis, and in fact affecting the same organs and tissues of sick dogs, especially the liver and kidneys, which significantly complicates diagnosis and significantly impairs prognosis. Complications of both leptospirosis and babesiosis have been shown to be the development of systemic inflammatory response syndrome (SIRS) and multiorgan dysfunction syndrome (MODS), which is often fatal. In the case of the associated course of leptospirosis and babesiosis, the dog's body actually receives a double lesion of the same organs and tissues, which often ends in death. In the associated course of leptospirosis and babesiosis, in addition to treatment, diagnosis is also difficult, because these diseases have similar symptoms and can mask each other. For example, relatively often leptospirosis in dogs is chronic, manifesting itself only in acute babesiosis $[15,16]$.

Leptospirosis is diagnosed most often by the reaction of microagglutination of blood serum in the laboratory $[17,18]$. Urine microscopy is also performed in a darkened field of the microscope, but this method is imperfect, because in the absence of leptospiuria in a sick dog or with the previous administration of antibiotics to the animal, the diagnosis will be false negative. The method of PCR diagnostics also has its drawbacks, as it can give a false-negative result in the accidental absence of the leptospira genome in the test sample of biological material $[19,20]$.

Therefore, the main aim of the study was to monitor the associated course of leptospirosis and babesiosis in dogs in the Sumy region during 2014-2019. The objectives of the study were to determine the number of sick animals, to establish the seasonal, breed, sexual dynamics of the incidence of dogs on this parasitocenosis.

\section{Materials and methods}

The studies were conducted during 2014-2019 in a private veterinary clinic «Vetservice» Sumy, Ukraine (reception and clinical examination of animals, blood samples, epidemiological evaluation and statistical processing of data) and in the serology department of the Sumy Regional State Laboratory State Service of Ukraine for Food Safety and Consumer Protection (study of dog sera in microagglutination reaction).

All experimental procedures and surgical interventions were performed in accordance with the «Regulations on the use of animals in biomedical research» and in accordance with the recommendations of the «European Convention for the Protection of Animals Used for Experimental and Scientific Purposes».

Blood samples were taken from dogs who got to the «Vetservice» clinic for treatment. The diagnosis of babesiosis was established directly in the clinic by the results of erythrocyte micro- 
scopy in thin smears of peripheral blood of sick dogs stained by Giemsa. The diagnosis of leptospirosis was established by the study of serum of sick dogs in the microagglutination reaction using 8 serogroups of leptospira (L. icterohaemorrhagiae, L. canicola, L. grippotyphosa, L. romona, L. tarassovi, L. hebdomadis, L. sejroe, L. bratislava) in the serological department of the Sumy regional state laboratory. The subjects of the study were clinically ill and suspected dogs with the associated course of leptospirosis and babesiosis, as well as blood samples from these animals. Babesia trophozoites were detected in erythrocytes under a microscope using immersion oil, a magnification of ocular $10 \times 90$, and the presence of antibodies to leptospira was detected by the presence of agglutination of leptospira in microagglutination reaction.

Statistical processing of the results was performed by methods of mathematical statistics, using Microsoft Excel. For each test item, if necessary, the arithmetic mean (M) and the standard error of the arithmetic mean (m) were determined. Differences with a significance level of more than $95 \%$ were considered significant. The degree of probability was assessed by Student's criteria.

\section{Results}

Studies were conducted to identify the dynamics of the associated course of leptospirosis and babesiosis in dogs (Table 1).

It has been experimentally established that the number of reported cases of the associated course of leptospirosis and babesiosis varies from 9 to 28 cases annually.

\section{Table 1}

The incidence of dogs in the associated course of leptospirosis and babesiosis for the period from 2014 to 2019

\begin{tabular}{cc}
\hline Year & Number of sick dogs \\
\hline 2014 & 15 \\
2015 & 11 \\
2016 & 9 \\
2017 & 28 \\
2018 & 20 \\
2019 & 16
\end{tabular}

Analyzing the monthly incidence of dogs in the associated course of leptospirosis and babesiosis, we see that the largest number of cases is registered annually in April-June (Table 2).

Table 2

Seasonal monthly incidence of dogs in the associated course of leptospirosis and babesiosis for the period from 2014 to 2019

\begin{tabular}{|c|c|c|c|c|c|c|}
\hline \multirow{2}{*}{$\begin{array}{l}\text { Number of the month from the } \\
\text { beginning of the calendar year }\end{array}$} & \multicolumn{6}{|c|}{ Year } \\
\hline & 2014 & 2015 & 2016 & 2017 & 2018 & 2019 \\
\hline 1 & 0 & 0 & 0 & 0 & 2 & 1 \\
\hline 2 & 0 & 0 & 0 & 0 & 0 & 1 \\
\hline 3 & 1 & 0 & 1 & 4 & 0 & 1 \\
\hline 4 & 1 & 3 & 2 & 4 & 3 & 7 \\
\hline 5 & 3 & 4 & 1 & 6 & 6 & 0 \\
\hline 6 & 2 & 1 & 0 & 5 & 2 & 1 \\
\hline 7 & 1 & 0 & 1 & 3 & 0 & 0 \\
\hline 8 & 3 & 1 & 1 & 1 & 0 & 1 \\
\hline 9 & 0 & 1 & 0 & 2 & 2 & 2 \\
\hline 10 & 4 & 0 & 1 & 1 & 2 & 2 \\
\hline 11 & 0 & 1 & 2 & 2 & 2 & 0 \\
\hline 12 & 0 & 0 & 0 & 0 & 1 & 0 \\
\hline
\end{tabular}


Analyzing the general seasonal dynamics of dogs in the associated course of leptospirosis and babesiosis for 6 years, we can say that this parasitocenosis is most often registered in spring (47 cases), to a lesser extent - in autumn (24 cases) and summer (22 cases), and rarely in winter (5 cases), which is probably due to favourable conditions for the survival of leptospira in the environment in spring and autumn (warm humid weather), and Ixodes mites, for which hot and cold weather are unfavourable (Table 3).

Table 3

Seasonal incidence of dogs in the associated course of leptospirosis and babesiosis for the period from 2014 to 2019

\begin{tabular}{cc}
\hline Season & Number of animals \\
\hline Winter & 5 \\
Spring & 47 \\
Summer & 22 \\
Autumn & 24
\end{tabular}

Analyzing the pedigree dynamics of the incidence of dogs in the associated course of leptospirosis and babesiosis, we see that purebred dogs get sick much more often than non-pedigree, which is probably due to a stronger immune system of non- pedigree animals, as well as the fact that owners keep purebred dogs more often (Table 4).

Table 4

Breed dynamics of the incidence of dogs in the associated course of leptospirosis and babesiosis for the period from 2014 to 2019

\begin{tabular}{ccccccc}
\hline Pedigree & \multicolumn{9}{c}{ Year } \\
\cline { 2 - 8 } & $\mathbf{2 0 1 4}$ & $\mathbf{2 0 1 5}$ & $\mathbf{2 0 1 6}$ & $\mathbf{2 0 1 7}$ & $\mathbf{2 0 1 8}$ & $\mathbf{2 0 1 9}$ \\
\hline Non-pedigree & 1 & 3 & 3 & 8 & 6 & 2 \\
Purebred & 14 & 8 & 6 & 20 & 14 & 14
\end{tabular}

Analyzing the sexual dynamics of the incidence of dogs in the associated course of leptospirosis and babesiosis, we see that for the period from 2016 to 2019, the number of diseases in females and males was approximately the same. During the period from 2014 to 2015, males were more often ill (Table 5).

\section{Table 5}

Sexual dynamics of the incidence of dogs in the associated course of leptospirosis and babesiosis for the period from 2014 to 2019

\begin{tabular}{cccccccc}
\hline \multirow{2}{*}{ Sex } & \multicolumn{9}{c}{ Year } \\
\cline { 2 - 8 } & $\mathbf{2 0 1 4}$ & $\mathbf{2 0 1 5}$ & $\mathbf{2 0 1 6}$ & $\mathbf{2 0 1 7}$ & $\mathbf{2 0 1 8}$ & $\mathbf{2 0 1 9}$ \\
\hline Males & 10 & 9 & 5 & 15 & 11 & 8 \\
Females & 5 & 2 & 4 & 13 & 9 & 8
\end{tabular}

\section{Discussion}

The experiment provides an opportunity to determine the prevalence of the associated course of leptospirosis and babesiosis in dogs of the Sumy region of Ukraine. However, depending on the conditions of keeping dogs and the availability of vaccination against leptospirosis and treatment with insecticides, the degree of infection of animals may differ each year $[1,2]$.

As a result of monitoring the incidence of dogs with the associated course of leptospirosis and babesiosis, it is proved that the disease is registered year-round with rapid peaks in spring and autumn, to a lesser extent - in summer and rarely - in winter. 
It has been experimentally established that purebred dogs suffer from the associated course of leptospirosis and babesiosis much more often than outbred ones, which is probably due to the strong immune response of non-pedigree animals, as well as the fact that owners keep purebred dogs more often. The severity of the disease also depends on many factors, including the immune status of the animal, its age, housing conditions and quality of feeding, the duration of the disease and the presence of comorbidities [4, 15].

During the period 2016-2019, the incidence of the associated course of leptospirosis and babesiosis in males and females was approximately the same. During the period of 2014-2015, males fell ill with the associated course of leptospirosis and babesiosis more than 2 times more often than females.

The practical value of the experiments is to monitor and determine the prevalence of the associated course of leptospirosis and babesiosis among dogs in Sumy region in the period from 2014-2019 with the establishment of seasonal, breed and sexual dynamics.

Study limitations. A limitation of the study is the incomplete coverage of the dog population with this monitoring, in cases of asymptomatic leptospirosis in animals, in cases of latent babesiosis, which forms immunization.

Prospects for further research. Investigation of the mechanism of pathogenesis of the associated course of leptospirosis and babesiosis in dogs and improvement of therapeutic regimens for this parasitocenosis.

\section{Conclusions}

The prevalence of the associated course of leptospirosis and babesiosis among dogs of the Sumy region of Ukraine in the period from 2014 to 2019 with the determination of seasonal, breed and sexual dynamics of this parasitocenosis.

Through practical research, it has been proven that for the last 6 years the associated course of leptospirosis and babesiosis in dogs is registered annually in the amount of 9 to 28 cases, and throughout the calendar year with the prevalence of clinical cases in spring and autumn. According to the general seasonal dynamics of the incidence of dogs associated with leptospirosis and babesiosis for 6 years, we can say that this parasitocenosis is most often registered in spring (47 cases), to a lesser extent in autumn (24 cases) and summer (22 cases), and rarely in winter (5 cases). Purebred animals get sick more often than non-pedigree ones. The incidence of dogs depending on sex is about the same.

The practical value of the experiments is to determine the prevalence of the associated course of leptospirosis and babesiosis among dogs in Sumy region.

\section{Conflict of interest}

The authors declare that they have no conflicts of interest.

\section{References}

[1] Ellis, W. A. (2010). Control of canine leptospirosis in Europe: time for a change? Veterinary Record, 167 (16), $602-605$. doi: http://doi.org/10.1136/vr.c4965

[2] Matijatko, V., Torti, M., Schetters, T. P. (2012). Canine babesiosis in Europe: how many diseases? Trends in Parasitology, 28 (3), 99-105. doi: http://doi.org/10.1016/j.pt.2011.11.003

[3] Llewellyn, J.-R., Hartmann, K., Bergmann, M. (2017). Epidemiologie und Prophylaxe der Leptospirose beim Hund. Tierärztliche Praxis Ausgabe K: Kleintiere / Heimtiere, 45 (3), 163-168. doi: http://doi.org/10.15654/tpk-160964

[4] Tiškina, V., Jokelainen, P. (2017). Vector-borne parasitic infections in dogs in the Baltic and Nordic countries: A questionnaire study to veterinarians on canine babesiosis and infections with Dirofilaria immitis and Dirofilaria repens. Veterinary Parasitology, 244, 7-11. doi: http://doi.org/10.1016/j.vetpar.2017.07.012

[5] Lau, S. F., Wong, J. Y., Khor, K. H., Roslan, M. A., Abdul Rahman, M. S., Bejo, S. K. et. al. (2017). Seroprevalence of Leptospirosis in Working Dogs. Topics in Companion Animal Medicine, 32 (4), 121-125. doi: http://doi.org/10.1053/j.tcam.2017.12.001

[6] Stokes, J. E., Kaneene, J. B., Schall, W. D., Kruger, J. M., Miller, R., Kaiser, L., Bolin, C. A. (2007). Prevalence of serum antibodies against six Leptospira serovars in healthy dogs. Journal of the American Veterinary Medical Association, 230 (11), 1657-1664. doi: http://doi.org/10.2460/javma.230.11.1657 
[7] McCallum, K. E., Constantino-Casas, F., Cullen, J. M., Warland, J. H., Swales, H., Linghley, N. et. al. (2019). Hepatic leptospiral infections in dogs without obvious renal involvement. Journal of Veterinary Internal Medicine, 33 (1), 141-150. doi: http://doi.org/10.1111/jvim.15340

[8] Forrest, L. J., O’Brien, R. T., Tremelling, M. S., Steinberg, H., Cooley, A. J., Kerlin, R. L. (1998). Sonographic renal findings in 20 dogs with leptospirosis. Veterinary Radiology Ultrasound, 39 (4), 337-340. doi: http://doi.org/10.1111/j.1740-8261. 1998.tb01617.x

[9] Solano-Gallego, L., Sainz, Á., Roura, X., Estrada-Peña, A., Miró, G. (2016). A review of canine babesiosis: the European perspective. Parasites \& Vectors, 9 (1). doi: http://doi.org/10.1186/s13071-016-1596-0

[10] Schoeman, J. P. (2009). Canine babesiosis : tick-borne diseases. Onderstepoort J Vet Res, 76 (1), 59-66. doi: http://doi.org/ 10.4102/ojvr.v76i1.66

[11] Kuleš, J., Bilić, P., Beer, L. B., Gotić, J., Crnogaj, M., Brkljačić, M., Mrljak, V. (2018). Glomerular and tubular kidney damage markers in canine babesiosis caused by Babesia canis. Ticks and Tick-borne Diseases, 9 (6), 1508-1517. doi: http://doi.org/ 10.1016/j.ttbdis.2018.07.012

[12] Winiarczyk, D., Michalak, K., Adaszek, L., Winiarczyk, M., Winiarczyk, S. (2019). Urinary proteome of dogs with kidney injury during babesiosis. BMC Veterinary Research, 15 (1). doi: http://doi.org/10.1186/s12917-019-2194-0

[13] Defauw, P., Daminet, S., Leisewitz, A. L., Goddard, A., Paepe, D., Duchateau, L., Schoeman, J. P. (2018). Renal azotemia and associated clinical and laboratory findings in dogs with Babesia rossi infection. Veterinary Parasitology, 260, 22-29. doi: http://doi.org/10.1016/j.vetpar.2018.07.012

[14] Bartnicki, M., Łyp, P., Dębiak, P., Staniec, M., Winiarczyk, S., Buczek, K., Adaszek, Ł. (2017). Cardiac disorders in dogs infected with Babesia canis. Polish Journal of Veterinary Sciences, 20 (3), 573-581. doi: http://doi.org/10.1515/pjvs-2017-0070

[15] Ajith, Y., Nithya, C., Arathy, S., Jeny, G., Meera, K., Shemeema, A. et. al. (2016). Clinical management of a Labrador retriever dog concurrently infected with Leptospira interrogans, Babesia gibsoni and Dirofilaria repens. Comparative Clinical Pathology, 25 (6), 1325-1330. doi: http://doi.org/10.1007/s00580-016-2325-y

[16] Reagan, K. L., Sykes, J. E. (2019). Diagnosis of Canine Leptospirosis. Veterinary Clinics of North America: Small Animal Practice, 49 (4), 719-731. doi: http://doi.org/10.1016/j.cvsm.2019.02.008

[17] Llewellyn, J.-R., Hartmann, K., Bergmann, M. (2017). Diagnose der Leptospirose beim Hund. Tierärztliche Praxis Ausgabe K: Kleintiere / Heimtiere, 45 (3), 170-177. doi: http://doi.org/10.15654/tpk-170039

[18] Miller, M. D., Annis, K. M., Lappin, M. R., Lunn, K. F. (2011). Variability in Results of the Microscopic Agglutination Test in Dogs with Clinical Leptospirosis and Dogs Vaccinated against Leptospirosis. Journal of Veterinary Internal Medicine, 25 (3), 426-432. doi: http://doi.org/10.1111/j.1939-1676.2011.0704.x

[19] Miotto, B. A., Tozzi, B. F., Penteado, M. de S., Guilloux, A. G. A., Moreno, L. Z., Heinemann, M. B. et. al. (2018). Diagnosis of acute canine leptospirosis using multiple laboratory tests and characterization of the isolated strains. BMC Veterinary Research, 14 (1). doi: http://doi.org/10.1186/s12917-018-1547-4

[20] Fraune, C. K., Schweighauser, A., Francey, T. (2013). Evaluation of the diagnostic value of serologic microagglutination testing and a polymerase chain reaction assay for diagnosis of acute leptospirosis in dogs in a referral center. Journal of the American Veterinary Medical Association, 242 (10), 1373-1380. doi: http://doi.org/10.2460/javma.242.10.1373 